blood pressure; in the latter there was a gradual fall. Four other brains are being investigated.

Vascular Theory of Shock: Excemia of Cannon.

I have not said anything yet about the vascular theory; it was formerly held that in "shock" the blood pressure fell, owing to its accumulation in the capillaries and veins of the abdominal organs. But it has been found that this is not the case. There is, however, a coucentration of the blood and stasis in the capillaries of the body generally, a condition which Cannon calls " exæmia." The plasma exudes through the capillary walls into the tissues; and in proof of this concentration is the fact that the hæmoglobin index is increased, likewise the blood cells count.

\section{TREATMENT OF SHOCK.}

Intravenous injection of salines proved useless; in some cases transfusion of citrated blood and gum saline solution, which was introduced on the assumption that it could not escape from the vessels, have raised the blood pressure and led to recovery ; in others, as in the four cases of which I have investigated the brains, these measures were unavailing. Crile recommends introduction of fluids by natural methods-e.g. Murphy's drip enema of 5 per cent. glucose and 5 per cent. soda bicarbonate solution. Stimulants seem to be useless, also injection of adrenalin and strychnine.

I have already pointed out that all causes of exhaustion of vital energy, whether psychical or physical, predispose to primary and secondary shock. In the case of the wounded in battle, thirst, exposure to cold and wet, delayed evacuation, rough and prolonged transport to hospital, and suffering with acute physical and mental agony conspire together to sap the vital energy, and when in consequence of circulatory failure and toxæmia the vital centres of the medulla become refractory and fail to discharge impulses the blood pressure falls progressively, and eventually in spite of all remedial measures the circulation and respiration cease.

In secondary wound and burn shock I did not find hæmorrhages; I conclude, therefore, that in cases of true "shell shock" this condition is due to physical effects produced by the forces generated by the explosion, but in some cases to the poisonous effects of gases absorbed while the man is lying unconscious.

In resuscitation from surgical shock practical experience shows that the treatment of the following phenomena have yielded satisfactory results-viz., (a) the fall of blood pressure; (b) the fall of the body temperature; $(c)$ the lessening of the volume of the blood. Experience shows that cases of hæmorrhage combined with little shock yield the best results.

In conclusion, I desire to say that a full report of the neurological changes will be published shortly by myself and Dr. Uno, of Tokio, who is at present engaged in making an investigation of the microscopic changes in my laboratory under my direction.

Bibliography.-Reports of the Special Investigation Committee on Surgical Shock and Allied Conditions, Medical Research No. 26. Surgical Shock, Crile and Lower, W. B. Saunders and Co.

Lieutenant-Colonels Walter Lidwell Harnett, I.M.S., and Francis Kenneth Kerr, R.A.M.C., and Dr. John Sinclair have been appointed Esquires of the Order of the Hospital of Sí. John of Jerusalem in England.

AN Extended CURFew IN DUBLIN.-For some months past, writes our Dublin correspondent, the curfew hours in Dublin have been from 10 P.M. to 5 A.M. Unfortunately, a number of attacks on parties of military or police occurred recently in the streets between dusk and curfew, and after giving warning that if such attacks did not cease curfew hours would be extended, last week the military authorities ordered that in future curfew would begin at 9 P.M. instead of 10 P.M. As heretofore medical practitioners clergymen, and nurses will be granted permits to be abroad on urgent professional business. The earlier hour of curfew will put great difficulties in the way of the various medical societies whose meetings have always hitherto been held in the evening. No doubt an attempt will be made to substitute afternoon meetings.
FURTHER NOTES* ON THE

\section{INTRAVENOUS INJECTION OF ANTIMONY}

\author{
TARTRATE
}

LEUCODERMA AND SKIN COMPLICATIONS; ADMINIS TRATION OF LARGE DOSES.

BY J. B. ChRistophERSON, C.B.E., M.D. CAMb.: F.R.C.P. LOND., F.R.C.S. ENG.,

TROPICAC DISEASES CLINIC, MINISTRY OF PENSIONS ; LATE DIRECTOK OF THE CIVIL HOSPITALS OF KHARTOUM AND OMDURMAN.

THE temperature chart which I am publishing with this communication is that of a Sudanese boy, aged 18, a student at the Gordon College, Khartoum, during the course of treatment by the intravenous injections of antimony (pot.) tartrate for kala-azar. He was admitted into the Khartoum Civil Hospital on March 9th, 1918, and was given $87 \frac{1}{2} \mathrm{gr}$. of antimony (pot.) tartrate in 86 days by intravenous injections, and discharged on. August 18th, cured so far as we could say. His was. a well-marked case of kala azar, with considerable enlargement of liver and spleen, and an intermittent temperature. He had noticed his illness for some months. Leishman-Donovan bodies found in splenic punctures on at least three occasions; no unfavourable complications such as ulceration of mouth, diarrhoea, cedema of legs, \&c. In August, 1920, two years after the course, he was quite well, and subsequently he was accepted for permanent Government service.

In publishing this case I do not wish to advocate the habitual administration of large doses of antimony tartrate even in diseases for which it is appropriate; antimony and its derivatives are powerful and potentially dangerous drugs, and in all cases the minimum dose necessary is the dose to be given. My object is to emphasise the fact that a very considerable amount of antimony tartrate may be injected if necessary into the veins without ill-effect, and to comment on certain incidents and complications which occur during the course of the administration of antimony tartrate for kala-azar, and for other diseases within my experience.

The temperatures in the ordinary native wards of the Khartoum Civil Hospital are taken by the native attendants, more or less under the supervision of the resident doctors, and are charted twice daily. The chart published with this article, representing four months, corresponds to the ordinary kala-azar chart made under these circumstances, recorded approximately at 7 A.M. and 7 P.M. It does not show the characteristic kala-azar deviations of temperature during the 24 hours of the day, as it would had it been registered every two hours. The rise in temperature till noon, followed by a drop, and a rise again at 4 P.M., forming a notch between 12 and 4 P.M., would then have been apparent. (A similar notch occurs at the same period during the night, ${ }^{1}$ making a notch in the chart during each period of 12 hours.)

The chart indicates: (1) That kala-azar is curable by antimony tartrate administered intravenously; this fact is now too well known to need comment. (2) That a large quantity ' ${ }^{2}$ the drug is sometimes necessary ( $87 \frac{1}{2} \mathrm{gr}$. in 86 days in this case) to effect a cure, and may be given with impunity, provided it is administered with care. (3) That 3 gr. of antimony tartrate ${ }^{3}$ may be injected every other day with beneficial results for 16 times in 33 days, totalling $60 \mathrm{gr}$. in 48 days, doses gradually increasing from 1 gr. to $3 \mathrm{gr}$. (see chart, May 26th to July 11th). (4) That this may be done soon after the preliminary but insufficient course

* Previous references to the writer's work on the subject appeared in THE LANCET, 1919, ii., 299, and 1920, ii., 528 and 1200 .

${ }^{1}$ Colonel C. Donovan, I.M.S., pointed this out to me and gave me chart to show it

2 A petient should be examined before commencing the course of injections in order to ascertain the existence or otherwise of contra-indications; stone fistula, and certain renal complication of ten associated with bilbarzia do not contra-indicate, whereas organic diseases of heart and kidney do contra-indicate injection for any reason. In far advanced cases of kala-azar it had best be withheld. My advice is, having ascertained that contra-indications re not present, inject with confidence.

3 I have sometimes injected $4 \mathrm{gr}$. ant. pot. tart. at one time in cases of bilharzia. 
125.5 $\mathrm{gr}$. in 41 days has been administered, during the early period of which $1 \mathrm{gr}$. antimony tarirate was given every day, afterwards every other day (see chart, March 17th to April 28th).

So much for the cumulative action of antimony. Of the more usual incidents attending the administration of antimony tartrate intravenously, the irritating cough at the time of injection-so constant when the potassium salt is used, but less frequent with sod. ant. tartratethe metallic taste in the mouth and throat, the salivation, colic ${ }^{*}$ and occasional diarrhoea, the nausea, retching, vomiting, the passage of a large quantity of urine two hours after injection, the occasional faintness ${ }^{\tilde{J}}$ and collapse with cold clammy perspiration-of all these incidents only the cough, the metallic taste, and a little tightness or discomfort in the chest are frequent ; in $\mathrm{mv}$ experience they may indeed be considered almost as symptoms of the injection. When the others

injected antimony tartrate, and their epithelium is liable to damage in the effort of these organs to eliminate it. To watch the effect of the antimony on the kidneys the urine should be examined after each injection. An attack of jaundice sometimes complicates the injections, indicating interference with the functions of the liver; but a much commoner complication indicating interference with the metabolism of the liver-cells by the antimony is shown by pains in the shoulders, and "lumbago" or muscular pains in arms or legs, sometimes so aggravated that the patient cannot turn over in bed. These pains appear to come on 4 or 6 hours after the injection, after a total of about $10 \mathrm{gr}$. have been given. At the same time the urine is loaded with crystals. In such a case it may be that certain products of digestion are not being elaborated as they normally should be by the liver, and the result is pain in various parts of the body of a rheumatic or

March

Kala-azar : Temperature and Treatment.

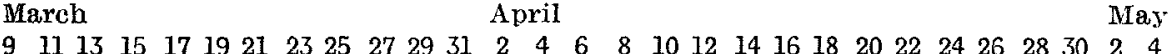

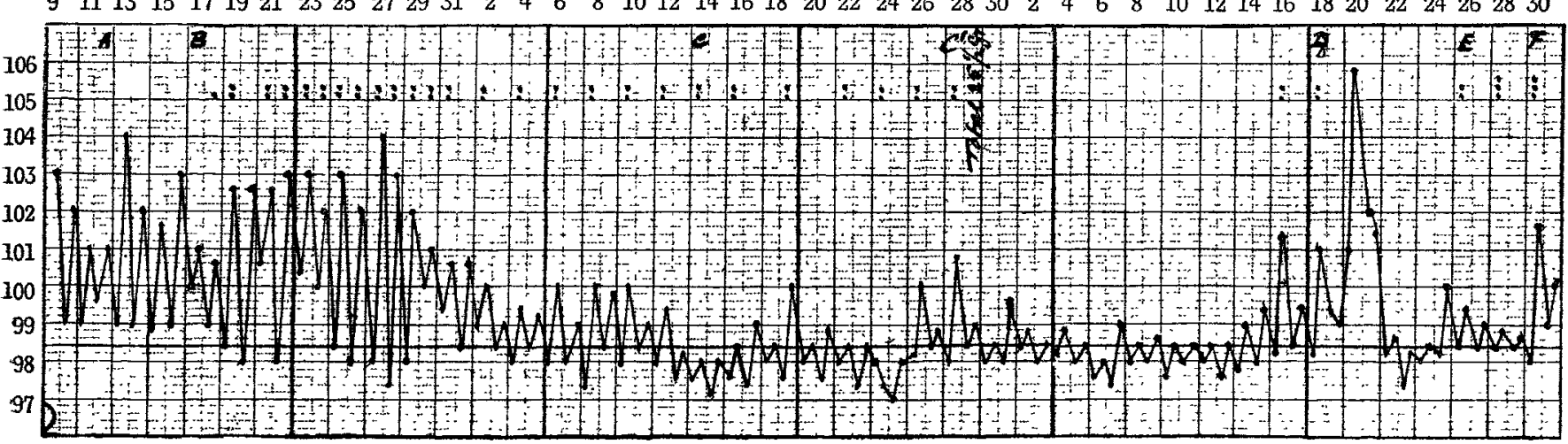

June

July

August

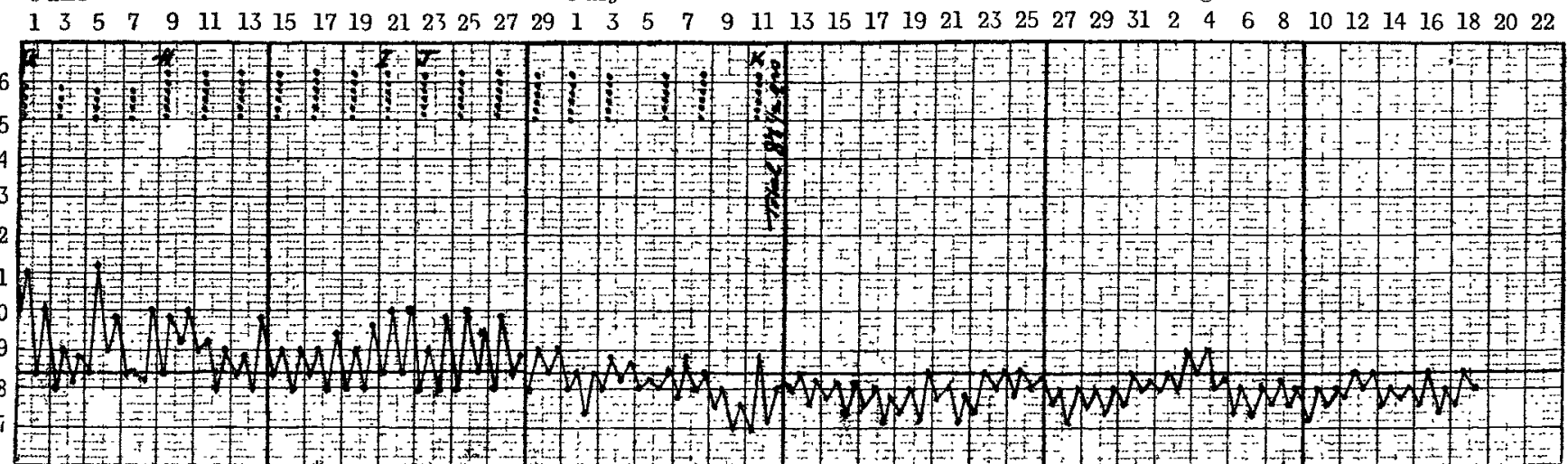

Fach dot in temperature column represents $0.5 \mathrm{gr}$. ant. pot. tartrate. Total on April 29th, $25.5 \mathrm{gr}$; on June $21 \mathrm{st}, 60^{\circ} 5 \mathrm{gr}$.; on July $11 \mathrm{th}$, $875 \mathrm{gr}$. A, Blood nesative for malaria. B, Leishman-Donovan bodies found ; splenic puncture. C, Spleen measures 6.2 inches below costal arch. $C^{\prime}$, Total $255^{\circ} \mathrm{gr}$ injected. D, Injections recommenced and suspended for a few days owing to reaction. E, Injections recomamenced; spleen $3 \frac{1}{2}$ inches below costal arch; $10 \mathrm{gr}$. quinine daily commenced. F, Splenic puncture negative; leucoderma patches appear. G, 2 gr. P.A.T. per dose. H, 3 gx. P.A.T. per dose. I, Total 62 gr. J, Weight 8 st. $71 \mathrm{~b}$. K, Injections suspended, spleen normal to percussion; weight 8 st. $8 \frac{1}{2} 1 \mathrm{~b}$; ; total P.A.T. injected $87^{\circ} 5$ gr.

occur they indicate a need for caution. Cough, retching, a little colic, and diarrhoea show that the maximum dose for the time being has been reached. Jaundice and more albumin in the urine than can be accounted for by the disease under treatment indicate, in $\mathrm{my}$ opinion, danger; when they occur permanent organic damage to liver and kidneys will result if the injections are continued. Both liver and kidneys deal with the

4 An Englishman of 40 , who had contracted bilharzia five years previously, complained of a pain in the abdomen half an bour after each injection when a dose of $2 \mathrm{gr}$. was reachod; this was alwavs followed by a diarrhoea motion, after which he felt quite well. Tolerance: In the course of antimony tartrate injections it some times happens, as in this case, that the patient retches, or, it may be, vomits immediately after the injection even of $0.5 \mathrm{gr}$. If care be taken not to increase the dose too rapidily and perseverance be exercised a tolerance is established. The patient under consideration retched on the table after first dose ( $\frac{1}{2}$ gr.). Next day when given $1 \mathrm{gr}$. he vomited once. A day was omitted; on the next day (4th) he vomited again (once) after $\mathrm{lgr}$. The drug was continued daily (1 gr.), and the patient established a tolerance at the eighth injection after $7 \frac{1}{2} \mathrm{gr}$. had been injected.

${ }^{5}$ In certain cases due to idiosyncrasy or perhaps to faulty arrangements, such as an indigestible meal previous to the injection, a patient will become dasky and drawn in the face, with contracted pupils and a slow feeble pulse; for such a patient the succeeding dose should be reduced and the arrangements adjusted. arthritic nature, owing to the presence in the circulation of "toxins" produced by the liver. These pains usually pass off, but if they are severe it may be advisable to suspend the injections or reduce the dose. ${ }^{6}$ They indicate interference by the antimony with the normal metabolism of the liver.

Leucoderma.

This Arab boy had one very notable and, I believe, rare complication during the course of injectionsnamely, disturbance in the pigment distribution of skin and mucous membrane; he became piebald. Leucoderma began to appear after a total of $30 \mathrm{gr}$. were administered. (See Fig. 1.) Though occasionally one sees rashes, erythemata generally, I had not before seen this profound pigmentary disturbance of the skin during injections of antimony tartrate. The leucoderma areas are well shown in the photograph.

6 The pains are experienced when the full dose ( $\left.2 \frac{1}{2} \mathrm{gr}.\right)$ is being given: it is sometimes sufficient to reduce the dose by $\frac{1}{2} \mathrm{gr}$. Another explanation of the "rheumatic" pains is that they occur when the drug reaches a certain concentration in the blood; this is not so, however, because if the amount of antimony is diminished bv a smaller individual dose they do nou recur, oven although the concentration is greater after the reduced dose 
They appeared all over the body, but chiefly on the face and head (even on the palms of the hands and soles of the feet). On the faco and body there were small, irregular, sharply outlined patches of absolutely white skin on the chocolate ground.

FIG. 1.

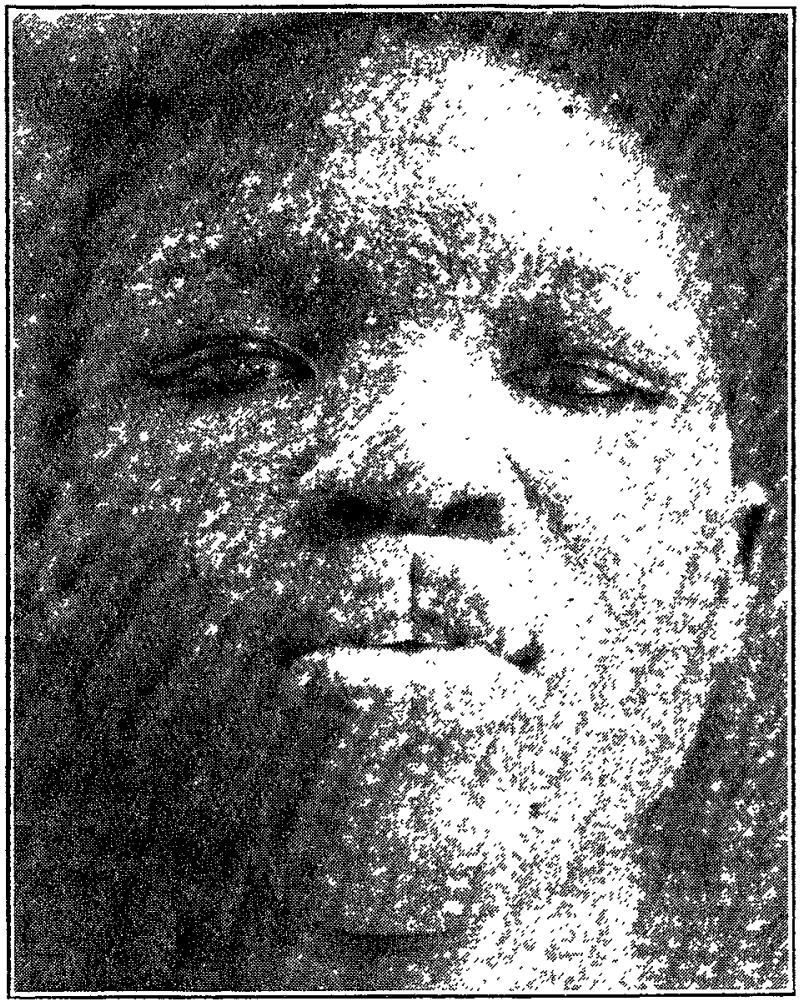

A. F., aged 18. Note white (leucoderma) patches on face, which extended all over the body; and lichen condition of skin.

Lichen planus.-A goose-skin or "lichen planus" condition (see Fig. 2) occurred somewhat earlier than the leucoderma and was distributed all over the body. I have noticed a "lichen planus" type of rash in other cases during injections of antimony tartrate, the shiny, velvety, smooth-all-over black man's skin becoming rough, dull, bumpy, and granular. Both these cuticular disturbances disappeared spontaneously, the "goose-skin" first, a month or two after the injections ceased; but, much to the boy's disgust, the skin of his lips remained a rosy pink instead of a dull red. These skin phenomena indicate that the skin is concerned in the elimination of the antimony from the patient; acting on this hypothesis, I have in two cases tried intravenous injections of antimony tartrate for chronic skin disease, psoriasis, with, I think, some success.

The doses of antimony tartrate recommended in bilharzia disease (20-30 gr.) have been described as " perilously high." They may be so ; but they cure the patient and do him no harm. " The risks of antimony poisoning are known, and one naturally works with care. For the cure of internal leishmaniasis even larger quantities of antimony tartrate are required than for bilharziasis (it may be $87 \mathrm{gr}^{2}$, as in this case). Kala-azar is a formidable disease, and larger doses are justifiable. "Give as much antimony as the patient will stand in such cases, carefully checking the results of each dose; but give as little as is necessary," appears to be the sound rule for guidance. In India colloidal antimony has been recommended in order to reduce the amount of antimony tartrate necessary for kala-azar.

In the case of oriental sore (Delhi boil) as little as 5-8 gr. ant. tartrate intravenously injected is often

7 It has been stated that a total of $10 \mathrm{gr}$, , or even less, is a sufficient quantity of ant. tartrate for the cure of bilharzia. A British army officer, who contracted bilharzia in Egypt two years previous

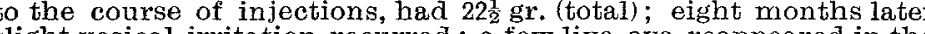
slight vesical irritation recurred; a few live ova reappeared in the urine, and I gave him another course of $30 \mathrm{gr}$. On the other hand an English boy of 8 years, from Nyassaland, was cured after a tota of 9 . The klling dose appears to be a variable one; some strain sufficient to cffect a permanent curc. To give as little as is necessary, and to stop dosage directly the object is attained, would seem to be the corollaries of the treatment. 'Trypanosomiasis appears to vesist antimony to a greater degrec than kala-azar. For none of these diseases does there appoar to be a fixed (total) curative dose any more than there is a fixed single lose. Intravenous medication is empirical; the capacity of the vascular system of the individual can be calculated, but different organisms vary in theix resisting power and different strains of the same organism vary in their power of resistance to A.T.

Doses also vary $^{8}$ with the individual patient-one person tolerates a larger dose of A.T. than anotherbut, speaking generally, it is a good rule to work on carefully until the objective is gained (or until danger threatens), in all diseases in which antimony appears to have a specific action.

The intravenous injection of antimony tartrate raises questions of considerable interest for the clinician. How is it that so large quantities of what we regard as a very potent and toxic drug may thus be introduced into the human body when the maximum dose by mouth is so small? The official (B.P.) dose of ant pot tartrate is $\frac{1}{24}-\frac{1}{6} g r .$, but one may with beneficial effect inject into the veins at one dose $3 \mathrm{gr}$., and repeat it every other day for 16 injections. (This is not a question of

Fig. 2.

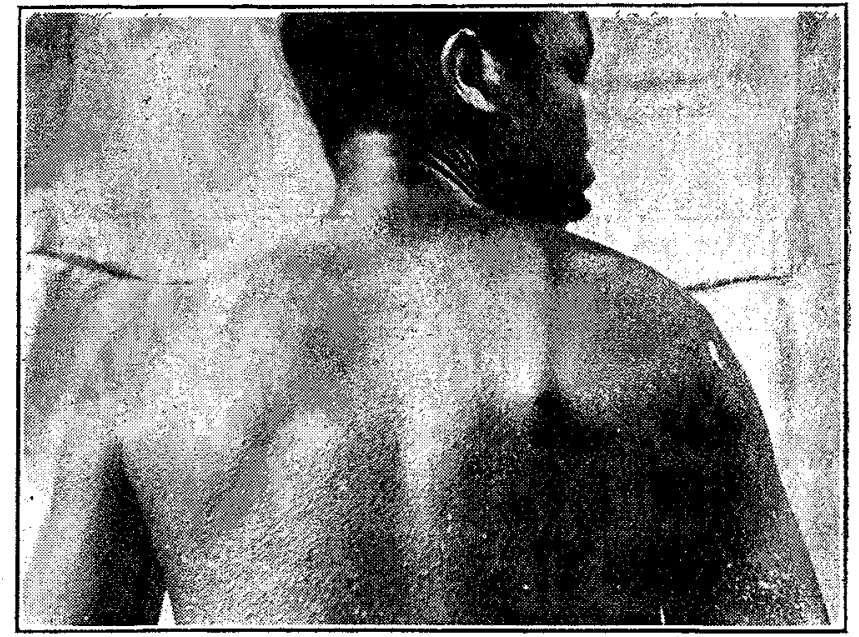

Showing lichen condition of skin of body during iniection of pot. ant. tartrate. Also incidentally showing white leusoderma patches on face and bodr.

establishing a tolerance for the drug because under no circumstances will a patient tolerate such doses by mouth.) Another interesting fact is that a small dose only can be given by the mouth and practically none hypodermically, on account of its irritating and necrosing action; whereas as much as $3 \mathrm{gr}$. (in $10 \mathrm{c.cm}$. or less water) can be given without any local injury, and with no harmful effect on the general economy, provided it is injected into the lumen of the vein. Regarded as a tissue, the blood is capable of resisting a very considerable amount of rough treatment.

The intravenous injection of antimony tartrate also raises interesting biological questions. I have pointed out, when writing on the effect of antimony tartrate on bilharziasis, that the antimony circulating in the blood, killing the adult worms, also penetrates the shell envelope and kills the myracidium within. It would

8 Young people take antimony tartrate very well. Older people with organs healthy except for the disease for which it is givenbilharzia: leishmaniasis-as a rule, take it well. In patients over 40 it should be given with more caution, Certain people appear to be unable to tolerate a full dose. It is always advisable to commence by a small dose of $\frac{1}{2} \mathrm{gr}$., increasing it cautiously; when the maximum single dose has been found it may be injected every other day-in England it is usually considered to be $2 \frac{1}{2 r}$. Some Soudanese I found tolerated 3 or even $4 \mathrm{gr}$. well, others showed signs of an over-dose when 1 gr. was reached. A patient in the lattor stages of kala-azar will obviously not tolerate as large doses of a cardiac depressant, such as antimony tartrate, as will the ordinary bilharzia patient. The fact is that young people especially tolerate the injections well, and people with organic disease (especially cardiac), badly : there is a certain number of apparently
healthy persons who are intolerant. 
seem probable that it acts in the same way towards the Leishman-Donovan body whose envelope is also permeable; moisture disorganises this body-a dry syringe is necessary when splenic punctures are made for diagnosis of kala-azar-and we also know by experience how difficult it is to find the Leishman-Donovan bodies in the splenic or liver smears post mortem and in the sections of dead tissues, so sensitive are they to the environment that directly death takes place they disappear-i.e., break up, and cannot be demonstrated.

We can understand these facts if there be free and easy communication through the limiting membranethe envelope of the L.D. body. The permeability of the L.D. body envelope or membrane is further indicated by the kala-azar temperature chart and also by the profound constitutional disturbances caused by the disease-the body inside the envelope manufacturing waste products, toxic to the human organism, which escape through the shell and are possibly replaced by pabulum passing in from without. Practical advantage is taken of the permeability of enclosing membranes of organisms when staining for the microscope, and I wish here to emphasise its clinical importance. Antimony tartrate kills the myracidium lying in the bilharzia ovum; after a few grains have been injected for bilharziasis the ova are very difficult to find in the urine, having apparently been arrested in their progress to the lumen of the bladder. This arrest is not easily explained if the ova are merely foreign bodies embedded in the tissues acting simply as such; if they were, they would behave in the same way before and after injection. Normally they are apparently vital bodies, having automatic action; it seems that only when the motor machinery inside the myracidium is killed by the antimony tartrate does it become a foreign body simply.

To return to the case of kala-azar under discussion. The enlarged spleen and liver did not satisfactorily diminish under A.T. injections alone; $10 \mathrm{gr}$. of quinine were therefore given every morning from 25/5/18 to 11/7/18 (47 days). ${ }^{10}$ Quinine was apparently necessary to this end; $10 \mathrm{gr}$. of quinine daily were given by mouth for 47 days, after which the spleen could not be felt, and the liver was not enlarged to percussion and palpation. Administration of quinine, together with injections of A.T., is thus advisable in kala-azar, when the spleen and liver do not satisfactorily diminish in size.

In bilharzia, kala-azar, and I believe also in trypanosomiasis, the initial effect of injecting antimony tartrate is a marked increase in constitutional disturbance, shown in bilharzia by increase of blood in the urine and aggravation of the local symptoms, in kala-azar by the rise in temperature often to $106^{\circ}$ or $107^{\circ}$, and in sleeping sickness by aggravation of symptoms. The first effect of intravenous injection of antimony tartrate is, therefore, to provoke the disease by liberation of toxins into the circulation. Later, as the blood stream becomes more laden with antimony, the parasites are killed. This point of view is supported "l by the initial increase of eosinophilia in bilharziasis during the course of injections; the differential count of the white blood cells afterwards becomes normal. (The large mononuclear cells also increase when antimony tartrate is injected in bilharzia.)

Summary.

To sum up. Experience seems to show that a few grains of antimony tartrate $(5-8 \mathrm{gr}$.) by intravenous injections may be sufficient to cure leishmaniasis of the skin, ${ }^{12}$ more (20-30 gr.) are necessary, as a rule, to bring about a cure in bilharziasis, and still more $(60 \mathrm{gr}$. , perhaps, and more) are necessary for leishmaniasis or

${ }^{9}$ Althongh L.D. bodies may be found plentifully in spleen and liver smears, they are hard to find in the peripheral blood of a patient, in spite of the fact that the splenic blood-vessels communicate freely with the systemic vessels. Possibly they dis integrate when they find themselves in the peripheral circulation. 10 The boy came from Cinga on the Blue Nile; possibly he had chronic malaria, although no malaria parasites were found in the

${ }^{11} \mathrm{It}$ is also supported by the temperature curve in kala-azar during the course of injections. Follow the chart publisbed.

Provided that the sores are not secondarily infected with a staphylococcal or streptococcal infection; otherwise thes will not heal so soon, although the leishmanic infection will clear up. kala-azar, and possibly still more (probably in repeated courses) for the cure of trypanosomiasis.

Antimony tartrate (pot. or sod.) when given intravenously in appropriate dilution and administered with care may be given in larger total doses than is generally supposed.

The blood, considered as a tissue, is probably capable of withstanding more physical and chemical ill-usage than any other organ; but owing to its structure and distribution it is obviously incapable of resisting micro organic invasion, and is the logical route for direct attack upon micro-organic and other diseases, particularly those of the blood stream itself.

The cure of parasitic diseases, such as bilharzia, kalaazar, trypanosomiasis, filariasis, dracunculus medi nensis, by a drug given intravenously (the drug itself if it acts directly, or a derivative if it acts indirectly) depends on: (1) the permeability of the enclosing membrane (or skin) of the parasite; (2) the penetrating power of the drug which in turn depends on its physical condition or chemical structure; (3) the toxicity of the drug to the parasite.

\section{THE OUT-PATIENT TREATMENT OF}

BILHARZIASIS,

WITH AN ANALYSIS OF 1000 CASES.

BY H. B. DAY, M.C., M.D. LoND., F.R.C.P. LoND., PHYSICIAN, KASR-EL-AINI HOSPITAL, CAIRO.

THE war-time discoveries of the Bilharzia Mission under R. T. Leiper, and of J. B. Christopherson, N. H. Fairley, and others concerning the early signs of infection, the life-history of the parasite, and a specific remedy against it, have rendered possible a campaign against the ravages of the disease in Egypt. Since bilharziasis affects no less than 80 per cent. of the asgricultural population in this country, it is evident that preventive measures must depend largely for their success on the awakening of an intelligent knowledge of the disease among the peasantry. It is hoped that by systematic instruction in the schools and by exhibition of posters and kinematograph films public interest will be aroused to the possibility of avoiding worm diseases and other infections and to the necessity of early treatment for curable maladies.

As a preliminary to work on a wider scale, it appeared desirable to test the methods of treatment advocated for bilharziasis, with a view of learning their possibilities and limitations. Experience soon showed that in-patient treatment was impracticable for most patients. The pressure on hospital beds prevented the admission of any but severe and complicated cases, and the average Egyptian would not stay in hospital unless seriously incapacitated. To overcome this difficulty permission was obtained from the Department of Public Health to erect a tent annexe at Kasr-el-Aini Hospital for the out-patient treatment of bilharziasis and ankylostomiasis. The particular subjects for investigation were twofold: (1) to test the practical value of out-patient treatment of bilharziasis as regards the attendance of patients and the efficacy of routine treatment; (2) to find the best methods of specific treatment and the minimum dosage and attendance necessary for the average case.

The annexe was opened in December, 1919, and put under the immediate charge of successive clinical assistants. To these doctors I am deeply indebted for all the clinical work and for invaluable assistance in the examination of the microscopic specimens necessary for scientific control. The annexe consists of marquee tents, pitched inside the hospital square, and arranged in two sections, male and female. They are provided with stretchers (on trestles) and blankets, and latrine accommodation is attached. A central marquee serves for examination and treatment. Each patient receives a numbered attendance card, which corresponds to a page in the registers in which all particulars are entered. At each visit a specimen of urine (or stool if indicated) is obtained and its appearance noted, 